\title{
Within-day variation in continuous hive weight data as a measure of honey bee colony activity*
}

\author{
William G. MEIKLE ${ }^{1}$, Brian G. Rector ${ }^{1}$, Guy MERCADIER ${ }^{1}$, Niels Holst ${ }^{2}$ \\ ${ }^{1}$ European Biological Control Laboratory, USDA - ARS, Campus International de Baillarguet, \\ CS 90013 Montferrier sur Lez, 34988 St Gely du Fesc, France \\ ${ }^{2}$ University of Aarhus, Faculty of Agricultural Sciences, Department of Integrated Pest Management, \\ Flakkebjerg, 4200 Slagelse, Denmark
}

Received 30 April 2008 - Revised 19 August 2008 - Accepted 29 August 2008

\begin{abstract}
Hourly weight data, from 4 honey bee hives placed on balances linked to dataloggers, were divided into two independent parts: (1) daily running average and (2) detrended weights, obtained by subtracting the running average from raw data. Weekly changes in running average weights, WCRAW, were correlated with food store changes but not adult or brood weights. Detrended weights showed daily fluctuation due to water and foraging bee movement and were modeled using sine curves, which fit all weekly subsets. Adult and brood populations, measured independently, were expressed as colony consumption rates via published per capita rates, and those consumption rates were correlated with sine amplitudes. Amplitudes were more sensitive to hive activity than WCRAW and unlike WCRAW detected high activity when foraging success was masked by high consumption Estimating food store changes with WCRAW and colony consumption with amplitudes reveals hive growth and activity without disturbing bees.
\end{abstract}

\section{Apis mellifera / hive weight / consumption rate / foraging activity}

\section{INTRODUCTION}

Data on the changes over time in the main biological components of honey bee colonies, i.e. adult and brood populations and food stores, are used by researchers to monitor hive health and to study behavior and population dynamics. Weighing hives daily or weekly is done by bee keepers and bee researchers (e.g., Harbo, 1993b; McLellan, 1977; Savary, 2006; Szabo and Lefkovitch, 1991) to help determine the best time to harvest honey or estimate food reserves for periods with no nectar flow. Weighing is fast, requires little training and is not disruptive to the colony so it can be done at any time of year. Weighing hives regularly, often, and with relatively high precision

Corresponding author: W.G. Meikle, wmeikle@ars-ebcl.org

* Manuscript editor: Klaus Hartfelder can provide useful information on colony dynamics. Buchmann and Thoenes (1990) first proposed using high-precision electronic balances, an idea also explored by Meikle et al. (2006).

Hourly weight data can considered as having two mathematically-independent parts: the daily running average weights and the withinday weight variation, hereafter referred to as the detrended weights. The running average weights, in which the weight for a given point in time is considered as the average weight of all weights 12 hours before and 12 hours after that point in time, removes the within-day variation. The running average weight is functionally equivalent to the average daily weight that most beekeepers and bee researchers monitor. Detrended weights, calculated as the difference between raw and running average data, show within-day variation, with a mean of zero for any given day, and can thus be attributed 
largely to bee activity. Buchmann and Thoenes (1990) observed this variation, but did not analyze it quantitatively. Meikle et al. (2006) fit sine curves to the detrended data. Here we used hive weight data gathered over 17 months to explore the relationship of the sine curve parameters to information on colony growth and activity. Weight data collected continuously were summarized and compared to hive inspection data gathered about every 2 weeks. Regression equations calculated from 2005 data were used to estimate colony measurements for 2006 and those estimates were compared to observed 2006 data.

\section{METHODS AND MATERIALS}

\subsection{Field setup}

Four honey bee colonies, two established in March 2004 (hives 1 and 2), and two in May 2005 (hives 3 and 4), were maintained in painted, 10 -frame, wooden Dadant brood boxes $(56 \mathrm{~L}$ capacity) (Ickowicz, Bollène, France). The hives were 0.5-2 m apart and were covered with telescoping lids with a weight on top to stabilize the hive in wind. Permanent water sources existed $<1 \mathrm{~km}$ away. The hives were each placed on top of two short wooden planks resting on stainless steel electronic balances $\left(\right.$ TEKFA $^{\circledR}$ model B-2418, Galten, Denmark). The balances had a maximum capacity of $100 \mathrm{~kg}$, a precision of $\pm 10 \mathrm{~g}$ and operating temperature range of $-30{ }^{\circ} \mathrm{C}$ to $70{ }^{\circ} \mathrm{C}$. The balances were linked to 12-bit dataloggers $\left(\mathrm{Hobo}^{\circledR}{ }^{\circledR} \mathrm{U}-12 \mathrm{Ex}\right.$ ternal Channel datalogger, Onset Computer Corporation, Bourne, MA, USA) and powered by a solar panel (BP Solar model 1230, Mimeure, France) as described in Meikle et al. (2006). The weighing system had an overall precision of about $\pm 30 \mathrm{~g}$. On 26 May 2005 new queens (Ickowicz, Bollène, France) were installed in colonies in hives 1 and 2, and new colonies, comprising a queen and $1 \mathrm{~kg}$ of adult bees, were installed in hives 3 and 4 . Hives were given syrup as needed at the end of May and early June 2005 . Average adult bee weight was estimated in September 2005 by shaking bees clinging to brood box frames from hives 1 and 2 into plastic boxes, placing the boxes in a freezer for $24 \mathrm{~h}$, counting the bees and weighing them individually on an electronic balance (Sauter model AR 1014, Albstadt Ebingen, Switzerland) with a precision of $\pm 0.001 \mathrm{~g}$. In September 2005, the hives were used to evaluate an application of entomopathogenic fungi on Varroa destructor fall and on hive health; no effects were observed on the hive weight or the weight of any colony component either among treated hives ( 2 and 3 ) or untreated hives (1 and 4) (Meikle et al., 2007). Rainfall was measured using a remote weather station $\left(\mathrm{Hobo}^{\circledR} \mathrm{Mi}-\right.$ cro Station, Onset Computer Corporation, Bourne, MA, USA).

\subsection{Hive components}

On 31 March, 10 May, 7 June 2005 and about every two weeks thereafter until 25 October 2005, the super and each brood box frame of each hive was weighed separately on a portable electronic balance (Kern \& Sohn model 12K 1N, Balingen, Germany) after shaking off the bees. Digital photographs were taken of each side of each frame using a 3.3 megapixel digital camera (Coolpix 990, Nikon France S.A., Champigny sur Marne, France), and the area of sealed brood and sealed honey per frame was estimated using ArcView 3.0 software (Environmental Systems Research Institute, Redlands, CA, USA). This weighing and photography procedure was conducted again for hives 2 and 4 on 11 April 2006 and every two weeks thereafter until 21 June.

Weights of brood and food stores were estimated from these data using the technique described by Meikle et al. (2006). Observed hive weight was divided into a "non-colony" component, consisting of hive support, e.g., brood box, lids, super, hive base, and 10 empty frames with only foundation comb, and the "colony" component, consisting of adult bees, brood, honey, pollen and wax (other than foundation comb). A brood box frame weight had 3 parts: (1) the wooden frame plus foundation comb; (2) the wax needed to build the honeycomb; and (3) the brood, honey and pollen in the cells. The wooden frame plus foundation comb was estimated by averaging the weight of 22 frames using an electronic balance (Sauter model 4021, Albstadt Ebingen, Switzerland), and the weight of a builtup but empty frame of honeycomb was estimated by weighing 10 frames entirely covered with empty honey comb, all of which were less than 1 year old. The weight of a frame taken directly from a hive was referred to as the observed frame weight.

Non-colony hive weight was calculated as the total weight of all hive components, with ten brood box frames plus foundation comb, and was determined for each hive at the start of the study. Colony 
weight was calculated as the difference between that weight and the observed total hive weight. Adult bee population weight, a component of colony weight, was calculated as the difference between the total hive weight and the sum of the weights of all colony and non-colony components after being shaken free of bees. Brood weight per frame was calculated by first estimating brood weight and surface area from brood frames without honey or pollen stores, converting those values to density using linear regression (SigmaPlot 2004, Systat, Inc.), and then using that density to estimate brood weight in frames that had both brood and food stores. After calculating brood weight for a given frame, food weight was estimated by subtraction.

\subsection{Datalogger output}

Hive weights were recorded hourly from June 2004 to July 2006. Weight data divided into two components: long-term changes represented by the 25-hour running average weight; and shortterm changes represented by the hourly detrended weight. The 25 -hour running average weight was calculated by averaging, for each hour, the observed colony weight over a period encompassing the preceding 12 hours, the hour in question, and the following 12 hours (for a total of 25 hours). Hourly detrended weight was calculated by subtracting the running average weight for a given hour from the raw data for that hour. This method separates shortterm $(\leqslant 25$ hours) weight changes, such as those due to daily bee activity, from long-term ( $>25$ hours) changes, such as those due to food collection. The Weekly Change in the Running Average Weight (WCRAW) was calculated for each day by averaging the 25-hour running average for 7 days starting 3 days before that day and ending 3 days after that day, and then subtracting the corresponding value for the day one week previous.

WCRAW data were evaluated with respect to daily weight changes in capped brood, the adult population and food stores as measured during the 11 inspections conducted in 2005, starting 11 May. The daily weight change for each colony component of each hive was calculated by subtracting the weight measured during a given inspection from that of the following inspection and then dividing by the number of days between the two inspections. Thus, the 11 inspections yielded 10 values per hive; component values were averaged across replicate hives within date. WCRAW values were aver- aged over the same time period and across replicates, then divided by 7 for a daily rate. Component weight changes were regressed on daily WCRAW and those relationships were validated using 2006 data.

To model the hourly detrended weights, a sine function,

$$
y=a \sin \left(\frac{2 \pi x}{b}+c\right)
$$

was fit to the data, where $a$ is the amplitude, $b$ is the period and $c$ is the phase (phase was not considered further). The data subset for a given day included a total of 168 hours, starting at 1:00 AM three days before that day until midnight three days after that day. Thus, the curve fit for a given day represented the best fit for the week in which that day was the middle day. Because these curves were fit to detrended data and WCRAW is calculated from the running average, they are mathematically independent.

Changes in food store weights represent the difference between food collection (total foraging effort) and food use (total colony consumption). Colony consumption rate was defined as the amount of food needed for brood and adults. Harbo (1993a) calculated that $163 \mathrm{mg}$ of honey are used to produce each worker bee until the cell is capped, and that daily consumption by an adult bee is about $5.3 \mathrm{mg}$. Total daily consumption by the colony, $C_{o b s}$, was therefore calculated as:

$$
C_{o b s}=\frac{0.0053 \times A d}{W_{A d}}+\frac{1}{14}\left(\frac{0.163 \times B r}{W_{B r}}\right)
$$

where $A d$ and $B r$ are the observed total adult bee weights and total brood weights $(\mathrm{g})$, respectively, and $W_{A d}$ and $W_{B r}$ are the average per capita weights $(\mathrm{g})$ of adult bees and brood, respectively. We assumed that the amount of food associated with a given capped cell would have been largely invested during in the two weeks before being photographed. This procedure ignored uncapped brood. Adult consumption rate can be expected to vary with the amount of work they do, so this estimate should be considered rough. In these analyses we assumed that water inflow, in the form of raw nectar and bee drinking, and outflow, due to evaporation and bee respiration, were roughly equivalent so water movement was ignored, but this aspect needs further work.

Daily food weight change and consumption rates for each store were regressed on average amplitude for the two weeks before each hive inspection. The 
two main differences between the WCRAW analysis and this one were that (1) the WCRAW analysis use brood and adult weight changes as dependent variables whereas the amplitude analysis used consumption rates; and (2) because amplitude was considered a function of bee movement, data gathered between 10 May and 7 June 2005, when hive 1 swarmed and hive 2 lost its queen, were excluded, as was data for hive 1 from 28 September 2005 onward when no worker brood were present. Regression equations from 2005 were validated using data from 2006.

\section{RESULTS}

\subsection{Hive components}

Fourteen frame photos from 8 sampling occasions showed capped brood without appreciable food stores and were used to estimate brood weight per $\mathrm{cm}^{2}$. In cases where the same frame was photographed more than once, most or all of the brood would have emerged in the two weeks between photos (Winston, 1992) so these samples were considered independent. The average (s.d.) weight of wooden frame plus foundation comb was 287 (24) g and average built-up frame weight was 492 (54) g. Estimated brood weight was regressed on capped brood surface area $\left(\operatorname{adj} . \mathrm{r}^{2}=0.75, \mathrm{~F}_{1,13}=\right.$ $39.75, P<0.0001)$; the line had a slope of 0.60 and an intercept of $100 \mathrm{~g}$. To calculate a predictive equation the line was forced through the origin. The slope, $0.72 \mathrm{~g}$ per $\mathrm{cm}^{2}$ $(\mathrm{t}=24.82, P<0.0001)$ represented the estimated capped brood density and was used to calculate brood weight for all frames containing both brood and food stores. The difference between the brood weight and the total observed weight for a given frame was attributed to food stores. A capped brood density of

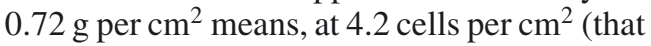
of foundation comb purchased from Ickowicz, Bollène, France and similar to that reported by Harbo, 1988), average brood weight, $W_{B r}$, was about $0.17 \mathrm{~g}$. Average adult weight, $W_{a d}$, was $0.128(0.024) \mathrm{g}(\mathrm{N}=309)$; weight was not corrected for honey in the bee crops, so it should be considered an upper bound. Harbo (1993a) reported a somewhat different $W_{B r}(0.13 \mathrm{~g})$ and
$W_{a d}(0.115 \mathrm{~g})$, but accurate weights would require repeated measurements throughout the season (Dietz, 1992). All hives had mite infestations and we assumed the impact of the infestations was equal among hives.

The adult population, brood, and food store weight dynamics were broadly similar among hives (Fig. 1) and to published results (Savary, 2006). By the end of May 2005, no queens were found in either hive 1 or 2 and they were requeened. Hive 1 lost its queen at the beginning of September 2005; within three weeks the weights of its adult bee population and food stores declined and capped brood weight dropped to zero (later brood were all drone). Hive 1 was combined with another hive in the apiary (not in the original experimental group) in November 2005. The younger hives, 3 and 4, had more adult bees at the last sampling at the end of October 2005 relative to hives 1 and 2.

\subsection{Datalogger output - Running average}

Running average colony weight showed hive growth from January 2005 to July 2006 (Fig. 2). After continuous weight loss through winter, with occasional rainfall spikes, hives 1 and 2 started to gain weight in March 2005 and continued to do so into May. Hive 1 produced three swarms for a total weight loss of about $0.94 \mathrm{~kg}$ honey and $3.77 \mathrm{~kg}$ adult bees (Meikle et al., 2006), assuming $20 \%$ of the swarm weight was due to honey in the bees' foregut (Harbo, 1993b). Weight spikes due to rainfall were also observed; Meikle et al. (2006) found that on average rainfall-induced weight gain lasted $<36$ hours. Balances for hives 1 and 2 had technical problems linked to low sunlight at the end of October and into November. After March 2006 only hives 2 and 4 were monitored.

Daily changes in each colony component were separately regressed on WCRAW using hive averages within inspection date (Tab. I). Daily food weight changes in were strongly correlated with daily WCRAW (Fig. 3). To evaluate whether the equation to estimate food stores using 2005 was robust, the 2006 


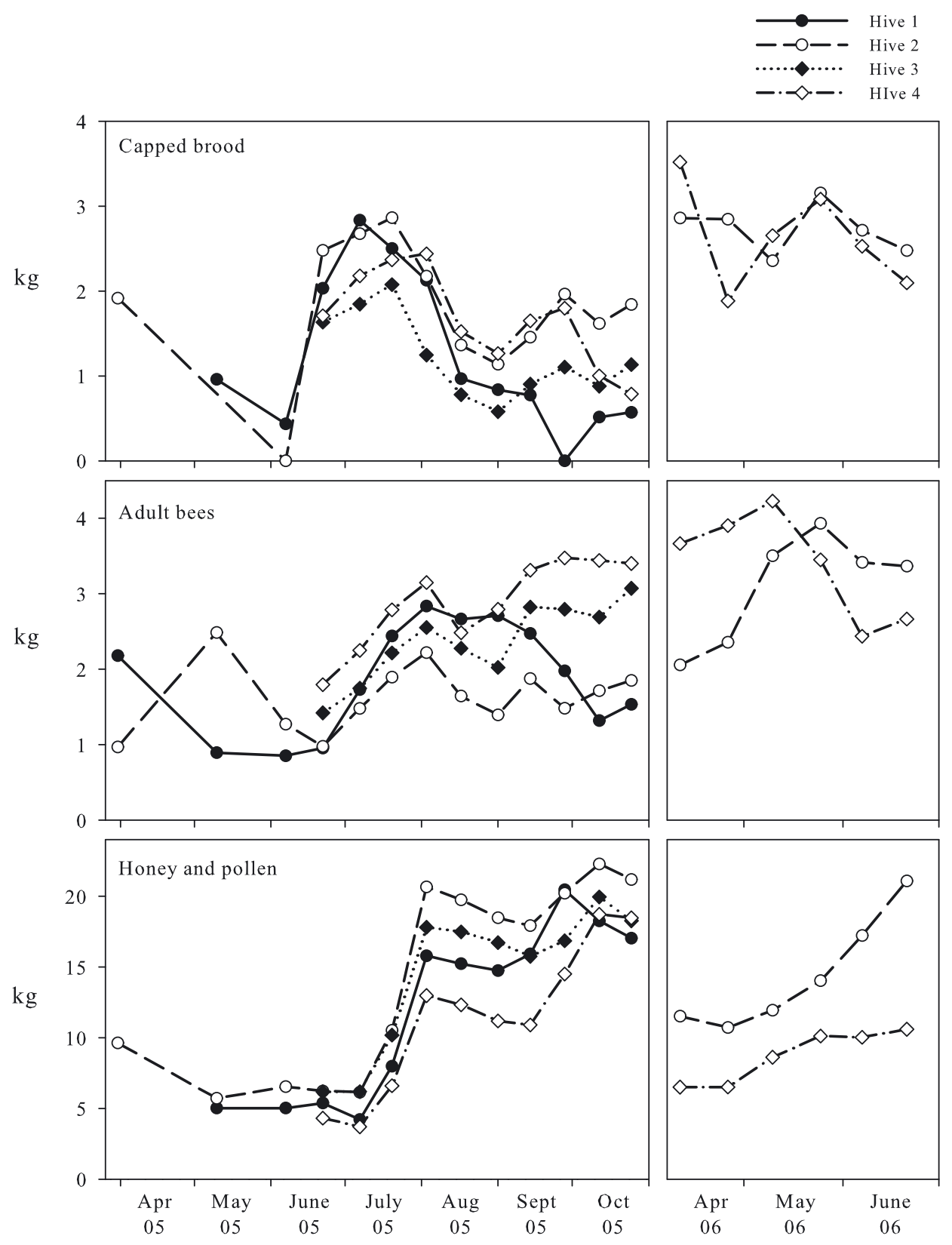

Figure 1. Weights of capped brood, adult bees and food stores over time, estimated by manually weighing hive parts on each sampling occasion, for 4 hives near Prades le Lez (34), France for June to October 2005 and April to June 2006. 


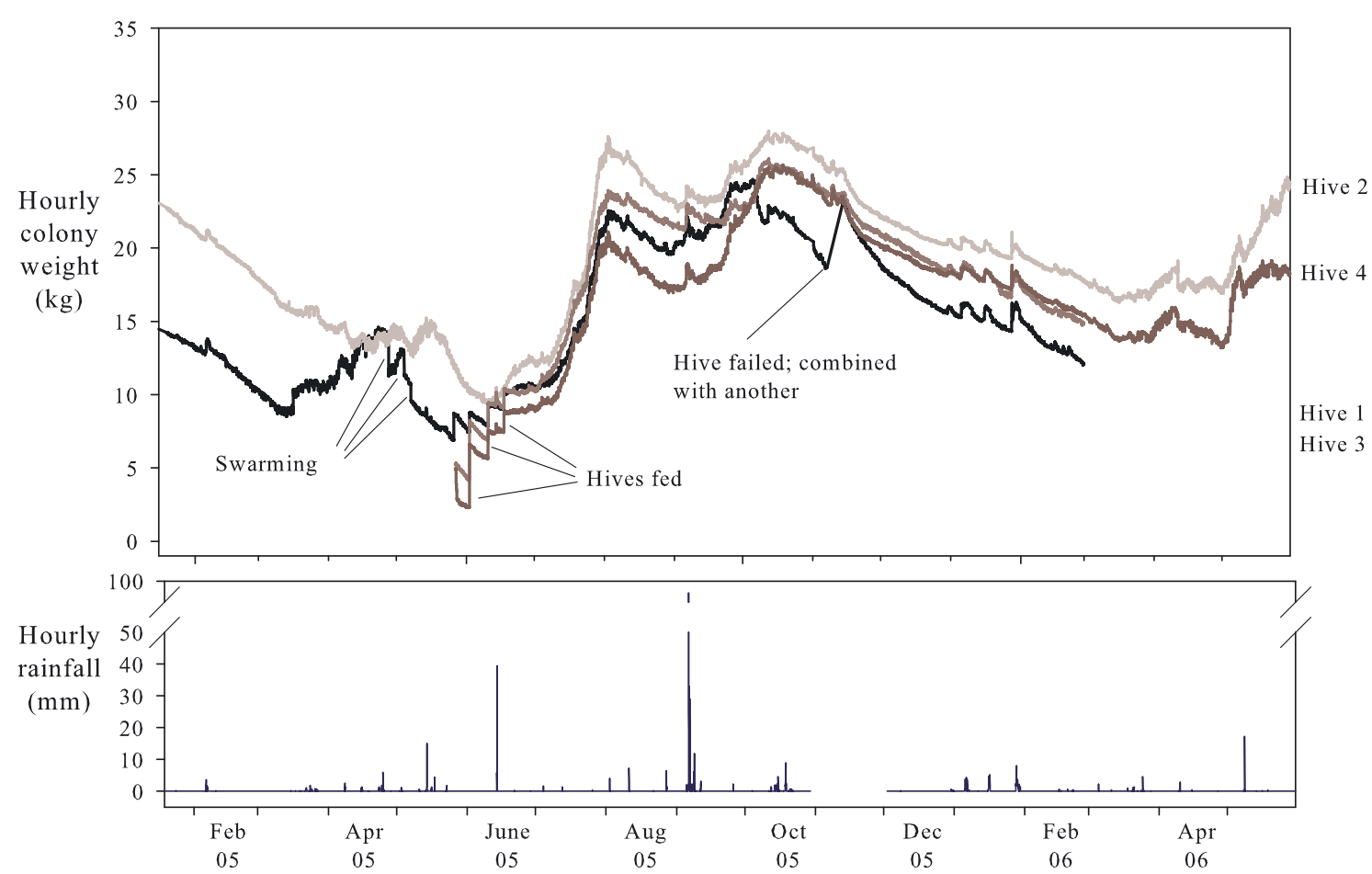

Figure 2. Bee colony weights for bee colonies kept near Prades le Lez (34), France, from January 2005 to June 2006.

Table I. Regression of bee colony component weights, measured directly every two weeks, on the weekly changes in the running average weight (WCRAW) and on detrended amplitudes. Food = daily change in hive food stores; Brood $=$ daily change in total brood weight; Adult $=$ daily change in total weight of adult bee population.

\begin{tabular}{lcccccc}
\hline Predictor & Indep. var. & Slope & Intercept & F value & $P$ & adj. $\mathrm{r}^{2}$ \\
\hline WCRAW & Food (F) & 0.989 & $5.26^{*}$ & 90.99 & $<0.0001$ & 0.90 \\
& Brood (Br) & 0.022 & $2.82^{*}$ & 0.063 & 0.81 & - \\
& Adults (Ad) & 0.068 & $-1.45^{*}$ & 3.460 & 0.10 & - \\
& $\mathrm{Br}+\mathrm{Ad}$ & 0.079 & $4.37^{*}$ & 0.65 & 0.44 & - \\
& $\mathrm{F}+\mathrm{Br}+\mathrm{Ad}$ & 1.053 & $-5.97^{*}$ & 304.97 & $<0.0001$ & 0.97 \\
Detrended & & & & & \\
amplitude & $\mathrm{F}$ & 4.11 & -319 & 32.75 & 0.0004 & 0.78 \\
& $\mathrm{Br}$ & 0.46 & $67^{*}$ & 2.97 & 0.12 & - \\
& $\mathrm{Ad}$ & 0.09 & 86 & 0.25 & 0.63 & - \\
& $\mathrm{Br}+\mathrm{Ad}$ & 0.55 & 153 & 8.45 & 0.0197 & 0.45 \\
& $\mathrm{~F}+\mathrm{Br}+\mathrm{Ad}$ & 4.66 & $-166^{*}$ & 40.03 & 0.0002 & 0.81 \\
\hline
\end{tabular}

* not significant at $\alpha=0.05$. 


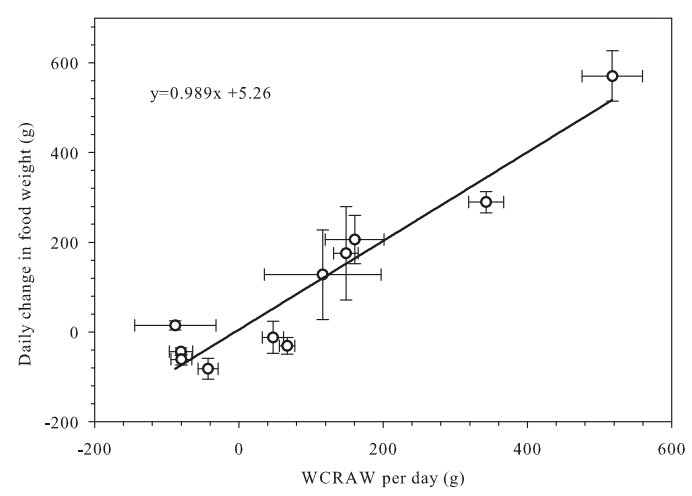

Figure 3. Change in the food weight per day regressed on the Weekly Change in the Running Average Weight (WCRAW). Values shown are averages and standard errors of 4 hives near Prades le Lez in southern France in 2005. The regression line is shown.

WCRAW data were multiplied by the 2005 regression slope (the intercept was not significant) and the resulting estimated values compared to observed 2006 data; estimated and observed food store weights were significantly correlated $\left(\mathrm{F}_{1,9}=22.25, P=0.0015\right.$, slope $=$ 0.716 , adj. $\left.\mathrm{r}^{2}=0.703\right)$. Estimated component weight changes were summed from 26 April to 21 June 2006 and compared to observed weights over the same time period to evaluate error over time. Estimated food stores based on WCRAW were $10.5 \mathrm{~kg}$ for hive 2 against an observed value of $10.0 \mathrm{~kg}$, and $1.8 \mathrm{~kg}$ for hive 4 against an observed value of $4.3 \mathrm{~kg}$. Hive 4 lost almost $2 \mathrm{~kg}$ capped brood between the first two inspections in 2006, which would partly explain the poor food weight estimate.

\subsection{Datalogger output - Detrended weights}

Detrended data showed a clear daily pattern although the pattern strength varied considerably within short time periods. Patterns in July were strong, for example, owing largely to nectar flow, while those observed in August, with little rainfall or nectar flow, were much weaker (Fig. 4). Swarming caused a large fluctuation in detrended weight followed by a reduced daily weight change because of the reduced bee population (Fig. 5). Sine curves fit all 7-day subsets of detrended weight data for all colonies $(\mathrm{N}=310$ for hive $1 ; 324$ for hive 2; and 205 each for hives 3 and 4). Curve periods were almost always between 22 and $26 \mathrm{~h}$ during nectar flows (see below) with average $\mathrm{r}^{2}$ values varying from 0.41 to 0.46 (range 0.10-0.82). However, each hive had from 15 to $25 \mathrm{~d}$ for which the fitted curves had periods of less than $20 \mathrm{~h}$; average $\mathrm{r}^{2}$ values for those curves tended to be lower and varied from 0.16 to 0.18 (range $0.10-0.29$ ).

Daily food weight change and consumption estimates were compared to daily amplitudes and WCRAW estimates for 2005 (Fig. 6) and 2006 (Fig. 7). Daily changes in food weight were correlated with daily amplitude but this relationship was indirect, since weight changes that last $>25 \mathrm{~h}$ are excluded from detrended data, and explained by the correlation between amplitudes and WCRAW $\left(\mathrm{F}_{1,9}=\right.$ $17.79, P=0.0022$, adj. $\left.\mathrm{r}^{2}=0.63\right)$. Food weight changes observed in the 2006 data were correlated with the values estimated using the equation from $2005\left(\mathrm{~F}_{1,9}=5.62, P=0.045\right.$, slope $=$ 0.242 , adj. $\left.\mathrm{r}^{2}=0.34\right)$, but as expected the relationship was poorer than that obtained using WCRAW.

Amplitudes were correlated with the colony consumption rate, $C_{o b s}$ in 2005 (Fig. 8) and this relationship was evaluated using data from 2006. The estimated colony consumption rate, $C_{e s t}$, calculated using the 2005 regression 

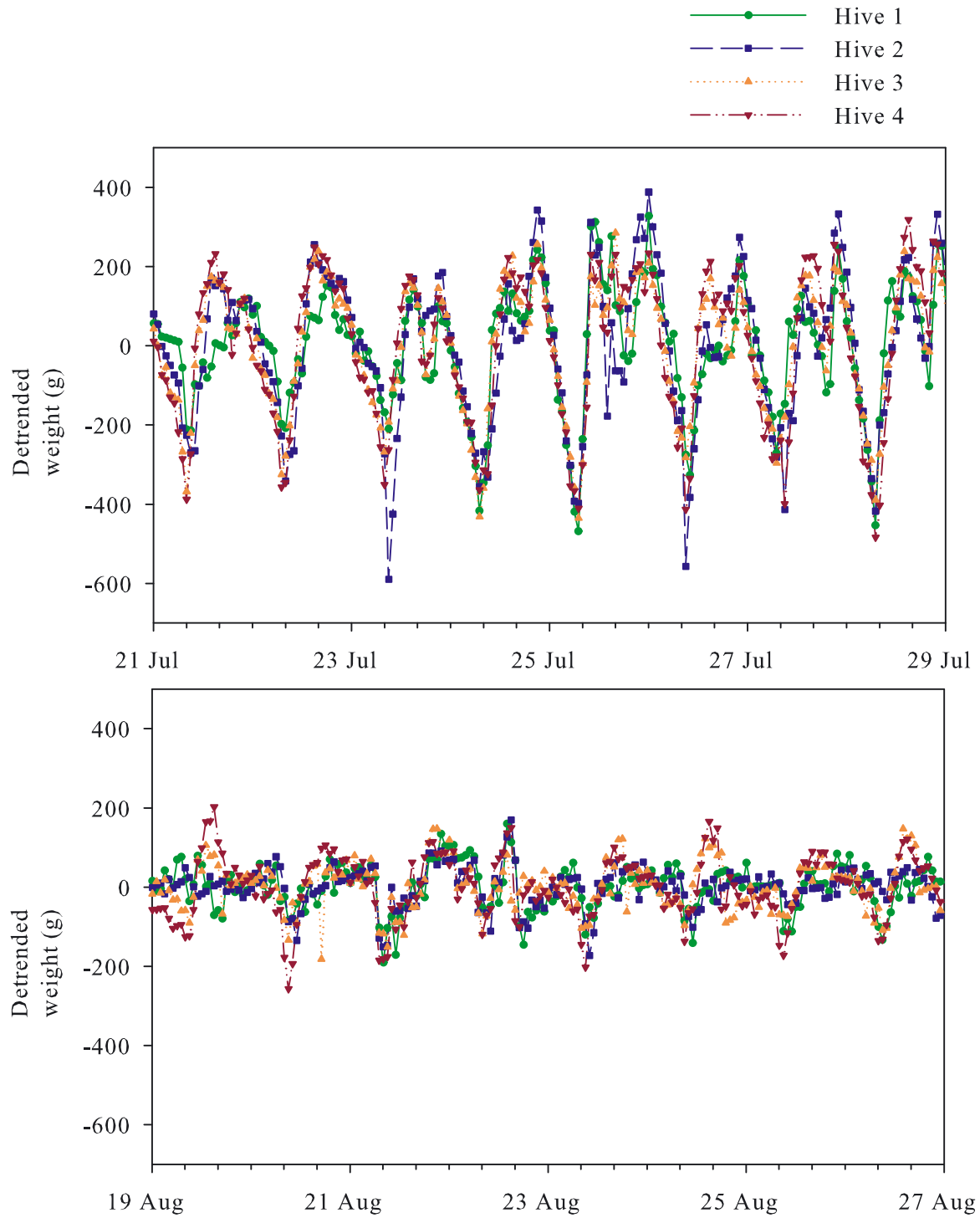

Figure 4. Examples of detrended weights from 4 bee colonies near Prades le Lez (34), France: Top: 21-29 July 2005; Bottom: 19-27 August 2005.

equation as $0.55 \times A m+153$ where $A m$ is the average daily amplitude for 2006 , was significantly correlated with $C_{o b s}$ for $2006\left(\mathrm{~F}_{1,9}=\right.$ $10.96, P=0.0107$, slope $=0.867$, adj. $\mathrm{r}^{2}=$ $0.53)$. Graphically, amplitudes detected large increases of activity in May and June, 2006, that did not register in the WCRAW, particularly in hive 2 (see Fig. 7). At that time both hives had large amounts of adult bees and brood relative to 2005 data, with associated food demands, resulting in little gain in food stores and thus little change in WCRAW, despite a large foraging effort. In this way the consumption by the colony masked the foraging effort from the point of view of the running average, but not from that of detrended 


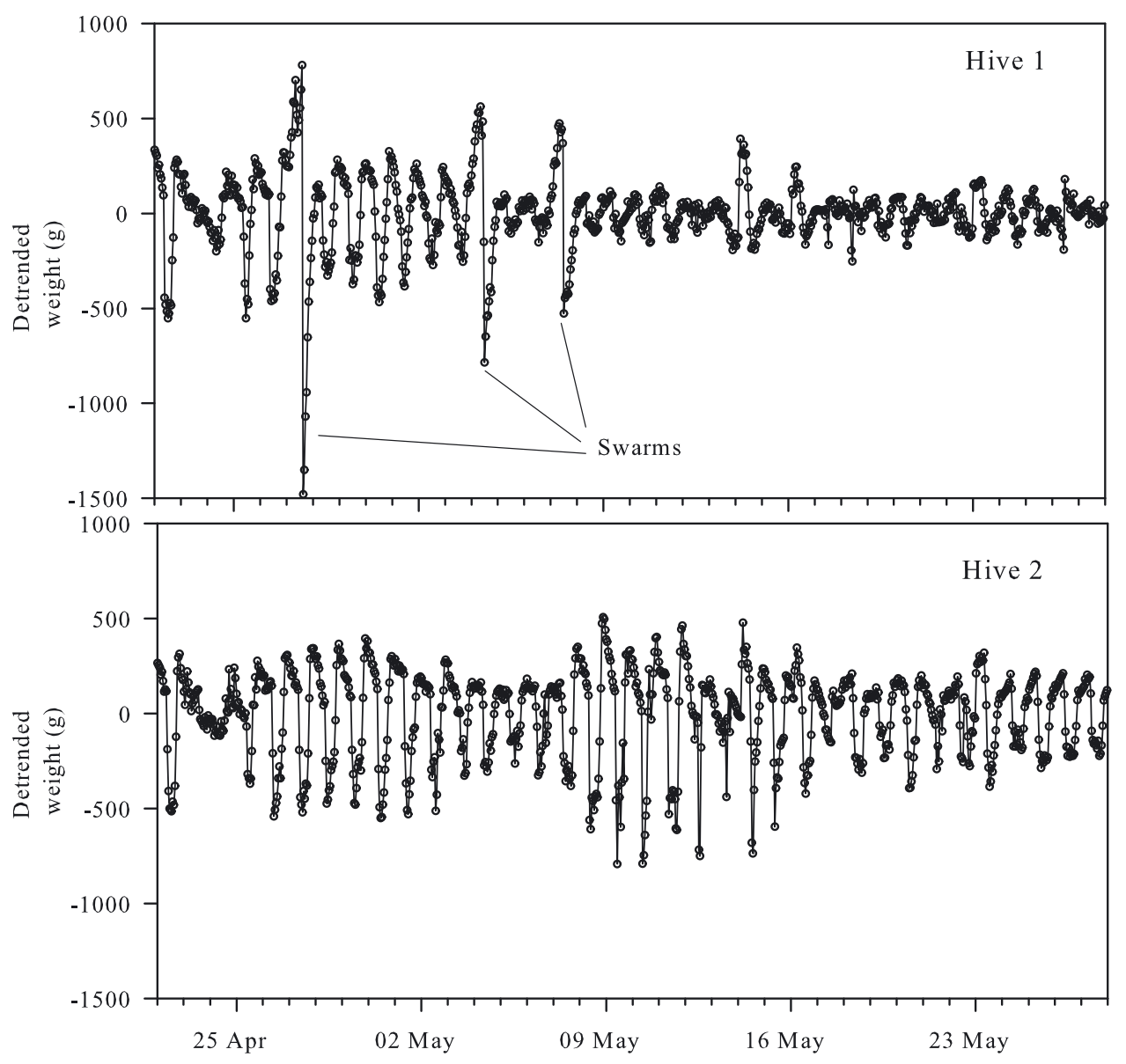

Figure 5. Detrended weights for hives 1 and 2 in from 22 April to 28 May, 2005, showing swarming events in hive 1.

data. Between the last two measurements of bee populations and food stores on 7 and 21 June, detrended amplitudes decreased from their highs in both hives but the levels of both amplitudes and WCRAW indicated an ongoing nectar flow. Amplitudes usually detected increases in activity in advance of WCRAW.

Detrended amplitudes and WCRAW data were used together to calculate the estimated foraging effort, $F_{\text {est }}$, for 2006, using the following relation: $F_{e s t}=C_{e s t}+0.989 \times W c$, where $W c$ is the daily WCRAW for 2006 and the coefficient 0.989 obtained from the 2005 regres- sion. $F_{\text {est }}$ was then regressed on the observed foraging effort for 2006, $F_{o b s}$, calculated as $F_{o b s}=C_{o b s}+S$, where $S$ is the observed daily change in food stores. $F_{\text {est }}$ and $F_{o b s}$ were strongly correlated with a slope close to one $\left(\mathrm{F}_{1,9}=26.13, P=0.0009\right.$, slope $=1.01$, adj. $\left.\mathrm{r}^{2}=0.74\right)$.

The minimum amplitude with a positive daily change in food weight was about $90 \mathrm{~g}$, so a nectar flow would reasonably be defined as a period of at least two weeks (ignoring gaps of 3 days or less) when the daily amplitude exceeded $90 \mathrm{~g}$. Using this definition to identify 


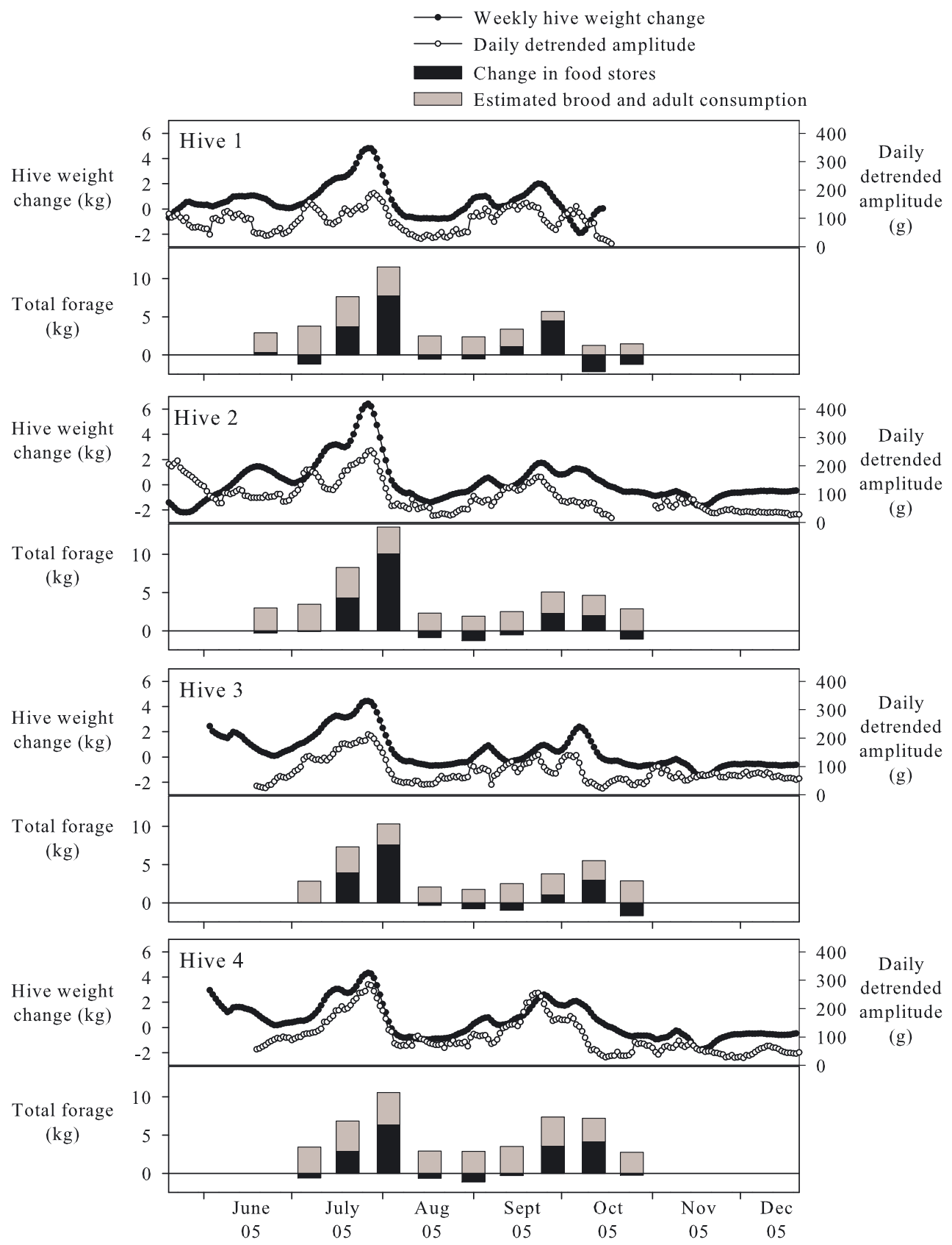

Figure 6. Daily detrended weight amplitudes and WCRAW values (upper graph in each group) and change in food weight with estimated colony consumption rate (lower graph in each group) for 4 hives near Prades le Lez (34), France in 2005. 


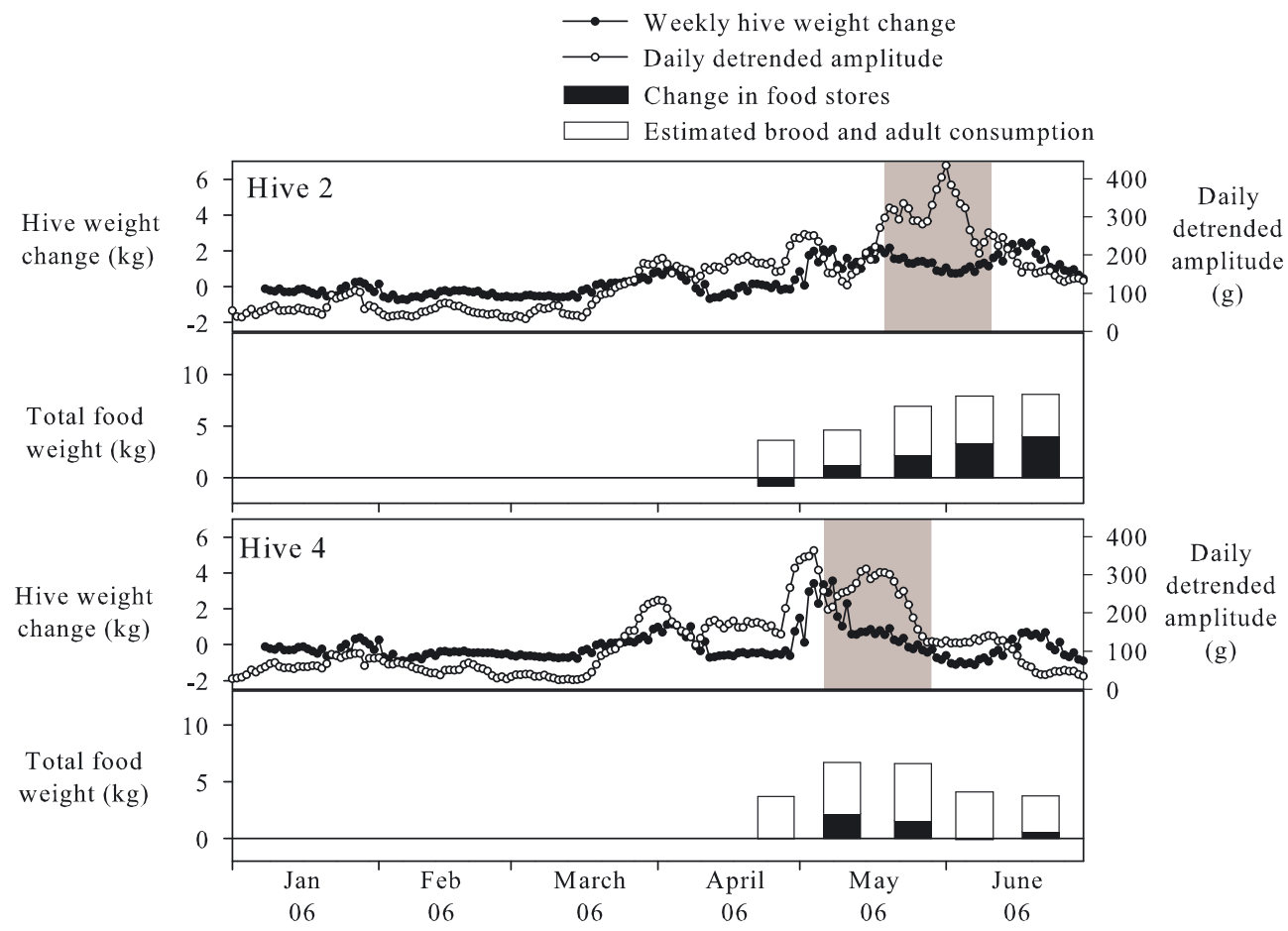

Figure 7. Daily detrended weight amplitudes and WCRAW values (upper graph in each group) and change in food weight with estimated colony consumption rate (lower graph in each group) for 2 hives near Prades le Lez (34), France in 2006. Gray areas indicate periods when detrended weight amplitudes indicated high levels of foraging activity but WCRAW did not.

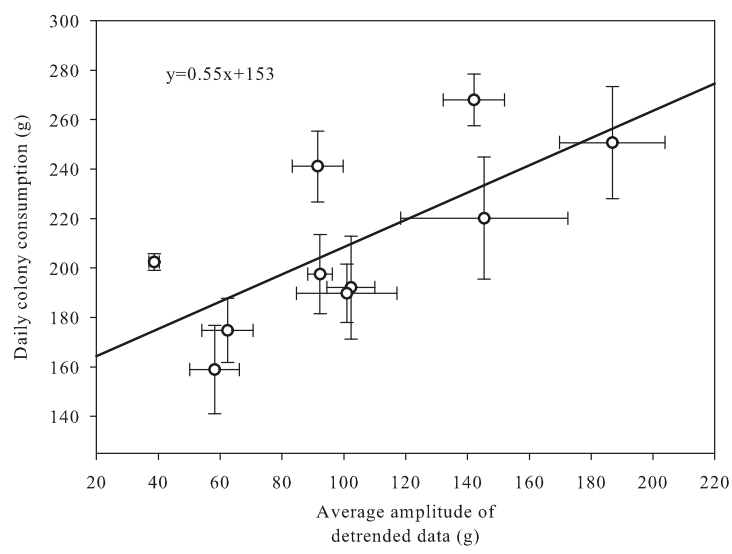

Figure 8. Change in the estimated capped brood and adult bee consumption rate per day regressed on the average amplitude of sine curves fit to the daily detrended colony weights. Values shown are averages and standard errors of 4 hives near Prades le Lez (34), France in 2005. The regression line is shown. 
nectar flows, average (s.e.) weight gain during a nectar flow was $8.86(1.58) \mathrm{kg}$, excluding data for the two hives in Spring 2005 that had lost their queens and lost considerable weight after initial gains. Of the five nectar flows observed in this study, from Sept. 2004 to June 2006, the differences in the starting date for a given nectar flow among the hives varied from zero (all hives started on the same day) to 35 days, and a given flow lasted from 26 (9.5) days to 96 (10.5) days.

\section{DISCUSSION}

Weighing honey bee hives hourly or more often, using dataloggers, yields data on hive growth and activity, provides precise information on timing and size of events such as swarming and unforeseen hive phenomena, and permits researchers to control for weight changes due to foraging and rainfall (Buchmann and Thoenes, 1990; Meikle et al., 2006). Thoenes and Buchmann (1992) observed hive abandonment due to tracheal mite infestation and were able to compare that with swarming. Meikle et al. (2006) quantified weight changes due to swarming and precipitation. The goal of this work was to develop ways to better exploit such continuous weight data.

Hourly weight data were divided into the 25-hour running average and the hourly detrended weights. The running average showed colony weight changes that lasted longer than 25 hours, and the hourly detrended data showed weight changes only within 25 -hours. The WCRAW data, calculated from the running average, were compared with changes in the weights of the adult and brood populations and food stores, and found strongly correlated with food store changes. That food weight changes constitute an important part of overall colony weight changes was not surprising; average food density was about 3 times than that of capped brood and thus were easy to measure. The average (s.e.) difference between minimum and maximum food weights per hive in 2005 was about $15.4(0.6) \mathrm{kg}$, compared to $2.2(0.4) \mathrm{kg}$ for capped brood weight and $1.7(0.1) \mathrm{kg}$ for adult weight, and food weight represented on average about $76 \%$ of the colony weight throughout 2005.

Detrended data, the hive weight variation within each 25 hour period, has not previously been evaluated as a source of information on hive growth and activity. Sine curves fit to the detrended data, and the amplitude, daily cycle, and coefficient of determination of those curves were examined with respect to the hive population and food collection. Amplitudes represented only the within-day weight change, consisting of foraging bees and water from respiration, nectar collection, honey ripening, drinking and evaporative cooling (Buchmann and Thoenes, 1990; Gary, 1992); the within-day average of the detrended data is zero so those data do not show longer-term weight changes. Amplitudes changed markedly during the active season, with high values during nectar flows and low values between flows, reflecting hive activity. An non-swarming colony with high amplitudes can be assumed to be collecting food but whether food stores are increasing would depend on the difference between the colony requirements and the amount of food being collected. This difference between foraging effort and food store changes was particularly noticeable in the spring 2006 dataset and was not surprising since hive population growth is usually at or near the maximum in the spring (Winston, 1992; Gould and Gould, 1988). If food needed for colony growth is being regularly replaced because of a nectar flow, the net quantity of stored food may change little if at all and the running average data might not directly detect either the population growth or the nectar flow. As shown in Figure 7, a sharp increase in amplitude not accompanied by an increase in the running average would indicate a nectar flow combined with an increase in colony-wide consumption, likely due to increased bee population size.

As noted by Buchmann and Thoenes (1990), the balance/datalogger combination can be a useful research tool for measuring colony activity, growth and reproduction. Using WCRAW and amplitude data together was shown here as a useful method for monitoring both changes in food stores and colony activity with a reasonable degree of confidence. 
Further work on the impact of important within-colony events, such as queen loss or disease outbreak, on detrended and runningaverage weight data will enhance the utility of these balances for monitoring colonies. Rapid or unexpected changes in weight parameters could indicate treatment effects in field experiments. These analyses can be made more precise by incorporating other techniques. For example, by electronically counting the number of foragers, weight change due to foragers and that due to water inflow and outflow can be estimated. Combined with other approaches, weight data such as those presented here can provide a more complete picture of hive dynamics.

\section{ACKNOWLEDGEMENTS}

The authors would like to thank B. Berton, F. Derouané, A. Herrera, W.A. Jones, C. Nansen and P.C. Quimby for field assistance and support, three anonymous reviewers for help in improving the manuscript, and the United States Department of Agriculture for funding the work.

Variations au cours de la journée du poids des ruches enregistré en continu comme mesure de l'activité de la colonie d'abeilles.

Apis mellifera / poids de la colonie / butinage / consommation alimentaire / variation horaire / enregistreur de données

Zusammenfassung - Tagesverlaufsschwankungen bei kontinuierlich registrierten Stockgewichtsdaten als Mass für die Aktivität von Honigbienenvölkern. Wir analysierten hier wie stündlich aufgenommene Gewichtsdaten Hinweise auf dynamische Veränderungen in Honigbienenvölkern liefern können. Das Wiegen von Völkern ist zwar eine schnelle und eingriffsfreie Massnahme, andererseits aber muss in regelmässigen $\mathrm{Ab}$ ständen und mit ausreichender Präzision gewogen werden, wenn man zuverlässige Informationen über Stockaktivität und Volksdynamik erhalten will. In dieser Studie wurden Bienenvölker in 2005 und im Frühjar 2006 in zweiwöchigen Abständen inspiziert. Die einzelnen Waben wurden gewogen und das Gewicht der verdeckelten Brut, der erwachsenen Bienen und der eingelagerten Futtervorräte wurden bestimmt. Die Völker waren auf elektronischen Waagen aufgestellt und mit Dataloggern verbunden. Stündlich registrierten Gewichtsdaten wur- den aufgeteilt in einen Mittelwert über 25 Stunden hinweg, als Langzeitmittel, und einen trendfreien Gewichtswert, als Kurzzeitinformation. Letzterer gibt die Abweichung der Rohdaten für die jeweilige Stunde von dem laufenden Mittelwert für die entsprechende Stunde an. Laufende Mittelwerte wurden auch benutzt, um die Wöchentliche Änderung im Laufenden Mittel (WCRAW, übersetzt WÄLM) zu berechnen, indem Wochenmittel von dem der jeweils folgenden Woche subtrahiert wurden. Die WCRAW-Daten wurden mit denen der Inspektionsdaten von 2005 für Gewichte der verdeckelten Brut und der adulten Bienen, sowie der Futtervorräte verglichen, und diese Vergleichsergebnisse wurden gegen die der in 2006 vorgenommenen Inspektionen verglichen. An die trendfreien Gewichtsdaten wurde eine Sinuskurve angepasst und die Parameter dieser Kurvenanpassungen wurden für WCRAWähnliche Analysen benutzt, ausser dass hier die Daten über die Brut- und Adultpopulationen in Verbrauchsraten umgerechnet worden waren.

Die WCRAW-Daten zeigten eine gute Korrelation mit den täglichen Veränderungen im Gewicht der Futtervorräte (Tab. I), aber nicht mit den Gewichtswerten für die Brut und für adulte Bienen. Die trendfreien Daten zeigten klare aber variable Tagesverlaufsmuster. Sinuskurven konnten an alle trendfreien Daten angepasst werden und diese wiesen stets eine Periodik zwischen 22 und 26 Stunden auf. Die Futtergewichtsdaten und die geschätzten Werte der Verbrauchsraten wurden für 2005 und 2006 mit den jeweiligen täglichen Amplituden der Sinuskurven und den WCRAW-Schätzwerten verglichen (Abb. 6 und 7). Die Amplituden und die Gewichte der meisten Komponenten zeigten eine signifikante Beziehung (Tab. I). Insbesonders die Beziehung zwischen den Verbrauchsraten für die Brut und adulte Bienen war signifikant mit der jeweiligen Amplitude korreliert (Abb. 8) und kann damit wichtige Informationen über den Volkszustand geben. Die Kombination der Wägungen mit der kontinuierlichen Datalogger-Information wurde hier benutzt, um Rückschlüsse über die Sammelaktivität, Wasserbewegungen, Schwarmvorgänge, Ruhezustände, sowie über Veränderungen in Futtervorräten und Futterverbrauch zu treffen. Diese Methode ist damit in der Lage, sowohl die Notwendigkeit invasiver Inspektionen zu reduzieren, als auch die Information aus solchen Inspektionen umfassender auszuwerten.

\section{Apis mellifera / Stockgewicht / Verbrauchsrate / Sammelaktivität}

\section{REFERENCES}

Buchmann S.L., Thoenes S.C. (1990) The electronic scale honey bee colony as a management and research tool, Bee Sci. 1, 40-47. 
Dietz A. (1992) Honey bees of the world, in: Graham, J.M. (ed.) The hive and the honey bee, Dadant \& Sons, Hamilton, IL, USA, pp. 23-71.

Gary N.E. (1992) Activities and behavior of honey bees, in: Graham J.M. (Ed.), The hive and the honey bee, Dadant \& Sons, Hamilton, IL, USA, pp. 269-373.

Gould J.L., Gould, C.G. (1988) The honey bee, Scientific American Library, HPHLP, New York.

Harbo J.R. (1988) Effect of comb size on population growth of honey bee (Hymenoptera: Apidae) colonies, J. Econ. Entomol. 81, 1606-1610.

Harbo J.R. (1993a) Effect of brood rearing on honey consumption and the survival of worker honey bees, J. Apic. Res. 32, 11-17.

Harbo J.R. (1993b) Worker-bee crowding affects brood production, honey production, and longevity of honey bees (Hymenoptera: Apidae), J. Econ. Entomol. 86, 1672-1678.

McLellan A.R. (1977) Honey bee colony weight as an index of honey production and nectar flow: a critical evaluation, J. Appl. Ecol. 14, 401-408.
Meikle W.G., Holst N., Mercadier G., Derouané F., James R.R. (2006) Using balances linked to dataloggers to monitor honey bee colonies, J. Apic. Res. 45, 39-41.

Meikle W.G., Mercadier G., Holst N., Nansen C., Girod V. (2007) Duration and spread of an entomopathogenic fungus, Beauveria bassiana (Balsamo) Viullemin (Deuteromycota: Hyphomycetes), used to treat varroa mites, Varroa destructor Anderson and Trueman (Acari: Varroidae), in honey bee colonies, J. Econ. Entomol. 100, 1-10.

Savary F. (2006) Le conservatoire de l'abeille noire provençale, Bull. Tech. Apic. 32, 115-120.

Szabo T.I., Lefkovitch L.P. (1991) Effects of honey removal and supering on honey bee colony gain, Am. Bee J. 131, 120-122.

Thoenes S.C., Buchmann S.L. (1992) Colony abandonment by adult honey bees: A behavioral response to high tracheal mite infestation? J. Apic. Res. 31, 167-168.

Winston M.L. (1992) The honey bee colony: Life history, in: Graham J.M. (Ed.), The hive and the honey bee, Dadant \& Sons, Hamilton, IL, USA, pp. 73-101. 